REVISTA ANDALUZA DE ANTROPOLOGÍA.

NÚMERO 2: PATRIMONIO CULTURAL Y DERECHOS COLECTIVOS.

MARZO DE 2012

ISSN 2174-6796

[pp. 168-173]

http://dx.doi.org/10.12795/RAA.2012.i02.11

\title{
MARCOS, SYLVIA (2010). Cruzando fronteras: Mujeres indígenas y feminismos abajo y a la izquierda. México: CIDECI-Universidad de la Tierra, Chiapas.
}

\author{
Alicia Reigada \\ Departamento de Antropología Social. Universidad de Sevilla
}

En su libro titulado Cruzando fronteras: Mujeres indígenas y feminismos abajo y a la izquierda, la investigadora mexicana Sylvia Marcos recorre espacios geográficos y culturales muy diversos para rescatar las voces de las mujeres y acercarnos a sus vivencias, cosmovisiones y propuestas. Un recorrido que realiza a la luz del pensamiento feminista y que permite plantear algunos de los debates y problemáticas que surgen de los encuentros entre los feminismos y los mundos de vida de las mujeres indígenas. Tales cuestiones suscitan un gran interés no sólo para la teoría feminista contemporánea, sino también para la antropología, disciplina preocupada por el estudio de la diversidad y el relativismo cultural, y para el pensamiento crítico en general.

Consideramos que es importante comenzar señalando el lugar desde el que ha sido escrito este libro. Como activista feminista y académica comprometida con las luchas de las mujeres indígenas de México, especialmente de las mujeres y los pueblos zapatistas, Sylvia Marcos ha querido elaborar un libro que se aleje del estilo y formato académico tradicional. De ahí que ella lo presente como un "libro-no libro" que recoge "retazos de insurrección en diferentes ámbitos". Es desde este compromiso social que se explica la decisión de publicar un libro como este en el CIDECI-Universidad de la Tierra (San 
Cristóbal de las Casas, Chiapas). Un espacio construido desde el trabajo diario de los compañeros y compañeras indígenas y enmarcado en un proyecto social y político implicado desde hace años en la lucha zapatista. Las imágenes de la pintora Beatriz Aurora acompañan los contenidos del libro e ilustran, a través del dibujo y los colores, la realidad y los sueños de los pueblos zapatistas.

El libro está estructurado en tres partes. La primera incluye escritos recientes y ponencias de la autora sobre sus intentos por conocer las experiencias de vida y de lucha de las mujeres zapatistas. La segunda parte contiene algunas reflexiones y propuestas teóricas sobre los feminismos indígenas. Por último, la tercera parte es un reporte de sus encuentros con otras mujeres activistas procedentes de diferentes universos culturales: las mujeres beduinas del desierto de Neguev, de Irán, Turquía o Palestina. Para reseñar el libro hemos rescatado y entrelazado algunas de las principales reflexiones que hilan el contenido del mismo y que están presentes, de una u otra forma, en distintos capítulos. Esta opción nos ha llevado a alterar, en algunas ocasiones, el orden en el que la propia autora ha estructurado los contenidos.

A partir de sus escritos y análisis sobre las mujeres zapatistas, la autora nos descubre cómo el neozapatismo, además de jugar un papel decisivo en hacer visibles las luchas de los pueblos indígenas en México, incluyó desde sus inicios las luchas por los derechos de las mujeres, impulsó su participación activa y reconoció sus contribuciones al movimiento. Las voces de las propias mujeres recogidas en el libro reflejan cómo fue a través de la organización dentro del zapatismo que muchas de ellas empezaron a tomar conciencia de sus derechos como mujeres. En concreto, la autora destaca el protagonismo desempeñado por aquellas mujeres que desde la fundación del Ejército Zapatista de Liberación Nacional (EZLN) situaron sus luchas como mujeres indígenas en el marco más amplio de las luchas de sus pueblos: "Las indias también hemos levantado nuestra voz y decimos: Nunca más un México sin nosotras. Nunca más una rebelión sin nosotras. Nunca más una vida sin nosotras" (Comandanta Ramona).

El relato etnográfico de diferentes encuentros en los que ha participado Sylvia Marcos, entre ellos el encuentro "Las Mujeres Zapatistas con las Mujeres del Mundo", celebrado en 2007 en el caracol de La Garrucha, muestra los avances experimentados desde que en 1993 se aprobara la Ley Revolucionaria de Mujeres hasta la actualidad. Se observa, así, cómo las mujeres han llegado a ser autoridad y a ocupar responsabilidades en los distintos órganos y consejos: como promotoras de salud, formadoras de educación, bases de apoyo, comisarias agrarias, miembras de las Juntas de Buen Gobierno, capitanas, milicianas o comandantas del CCRI.

Es al hilo del acercamiento a la realidad de las mujeres zapatistas que la autora nos invita a pensar sobre la relación entre teoría feminista y experiencia zapatista. Entendemos que es en este punto donde reside una de las principales contribuciones del presente libro. 
“Cómo unir esos dos mundos, el de la teoría feminista y la cosmovisión indígena?” Para afrontar este reto la autora plantea la necesidad de "otra teoría". Una teoría que sea capaz de atender al contexto en el que se desenvuelve la vida de las mujeres zapatistas, que contemple la forma de ver el mundo propia de los pueblos indígenas y que sea capaz de romper con las herencias de la colonialidad del poder.

Ello supone, en primer lugar, considerar las características filosóficas del mundo maya, donde "prevalece una pertenencia a la totalidad, al universo, al todo"; un comunitarismo que se diferencia radicalmente del individualismo de la filosofía occidental. También es necesario escuchar y comprender "cómo las mujeres ven el mundo, la naturaleza, cómo se ven a sí mismas, a sus compañeros y sus creencias". "Qué dicen, cómo lo dicen, qué reclaman y qué aportan desde su cosmovisión". A partir de ahí, sería posible comprender mejor su concepción de la dualidad hombre/mujer, ese "podemos caminar juntos" que se inscribe en los fundamentos cosmológicos mesoamericanos del "acuerdo" y el "equilibrio" y que, en opinión de la autora, no ha sido comprendido en profundidad por el feminismo. El subapartado en el que se reflexiona sobre la reformulación del término "Derechos Humanos" que se hace desde el feminismo de los pueblos indígenas ayuda a comprender la visión propia y las características específicas del concepto de género del que parten las mujeres indígenas y el lugar que atribuyen a la espiritualidad indígena.

Desde esta perspectiva también sería posible entender el modo en que llegan a ser autoridad basándose en el "mandar obedeciendo", una frase cuyo contenido político es originaria del pensamiento y la lengua maya tojolabal de Chiapas y que expresa la búsqueda de otra forma de hacer política, como bien explica Sylvia Marcos siguiendo las aportaciones de Carlos Lenkersdorf. Junto a ello, la autora atiende al derecho a conservar sus lenguas y al modo en que se relacionan con la Castilla, y reflexiona sobre la relación entre la oralidad, el género y la espiritualidad indígena. Frente a la tendencia a interpretar la oralidad en términos de inferioridad y atraso, habría que considerar los dispositivos retóricos propios de las religiones orales (las redundancias, paralelismos, mitos, leyendas, cánticos, símbolos y metáforas) y el carácter híbrido de estas tradiciones.

Igualmente híbrido es el conocimiento y las creencias sobre salud y enfermedad que conservan y reivindican los pueblos indígenas, donde las mujeres curanderas y parteras ocupan un papel muy destacado. A fin de contextualizar adecuadamente la medicina popular, la autora la sitúa en el marco religioso en que se inserta: el de la cosmovisión mesoamericana y las tradiciones prehispánicas. El libro nos muestra cómo la medicina popular se resignifica al mezclarse con elementos de diferentes periodos históricos y se aleja del modelo de medicina institucionalizado y dominante. Así lo reflejan, entre otros de los ejemplos que se citan, el que en el mundo azteca las parteras actuaran como sacerdotisas en los rituales relacionados con los nacimientos o el que estas prácticas curativas tengan como centro la curación del espíritu, del alma. Como en otros campos 
de la vida social, su medicina está impregnada de la visión holística y de la espiritualidad propia de los pueblos indígenas.

Pero el interés de sus anotaciones y análisis sobre los mundos de vida de las mujeres zapatistas reside también en la posibilidad que nos ofrecen para afrontar determinadas problemáticas y debates que se hallan en el centro de la teoría feminista contemporánea. Ya en las primeras páginas del libro la autora cuestiona simultáneamente la globalización hegemónica, presentada como un proceso unívoco, irrevocable y positivo, y el feminismo hegemónico, que excluye otras visiones y prácticas feministas como las que protagonizan las mujeres indígenas. Si frente a la globalización hegemónica apuesta por la 'globalización desde abajo, en la línea abierta por autores como Boaventura de Sousa Santos, frente a la homogeneización del feminismo hegemónico defiende la necesidad de situar a las mujeres dentro de sus contextos sociopolíticos, culturales y económicos, siguiendo la propuesta de Chandra T. Mohanty.

Ello nos conduce a un debate crucial, centrado en la cuestión de las diferencias, que cobra peso dentro del feminismo a partir de la década de los ochenta, de la mano de las revisiones y propuestas planteadas con especial fuerza desde el feminismo afroamericano. Recordemos que las críticas al feminismo occidental, blanco, de clase media y heterosexual (bell hooks, 1981, 2004 [1984]; Davis, 2004 [1981]) vienen a plantear la importancia de atender no sólo a las diferencias y desigualdades entre hombres y mujeres, sino también a las diferencias existentes entre las propias mujeres. En la base de esta revisión se establece una crítica a esa concepción unitaria del sujeto "Mujer" construida desde el feminismo hegemónico occidental. Como bien plantea Chandra Talpade Mohanty (2002) cuando se propone teorizar la experiencia desde una 'política de la ubicación', no existe una experiencia de opresión de las mujeres común y universal. Es desde esta perspectiva desde la que Sylvia Marcos sugiere hablar de los 'patriarcados' (y no del 'patriarcado') y de los 'feminismos' (y no del 'feminismo'), con el objetivo de contemplar esa complejidad Igualmente importante le parece entablar "diálogos" que nos permitan reconocernos en esas diferencias y usarlas para lograr metas comunes, para crear lazos de solidaridad y relaciones de reciprocidad desde la "globalización desde abajo". La propuesta que sigue para establecer estos "diálogos" es aquella denominada "hermenéutica diatópica" por Baoventura de Sousa Santos. La última parte del libro, en la que nos traslada a sus encuentros con las mujeres beduinas, iraníes, turcas y palestinas, plantea el tema de las diferencias - en las formas de opresión y en los proyectos emancipadores- y el de las alianzas, los posibles diálogos Sur-Sur. Algunos de los dilemas que afrontan estos colectivos de mujeres, por ejemplo en la forma en que revisan sus tradiciones religiosas y textos sagrados o en que viven el Islam, le recuerdan a los que la propia autora ha vivido en México. Al igual que en el caso de las mujeres indígenas zapatistas, para acercarse a la experiencia de las mujeres beduinas, iraníes, turcas o palestinas es necesario ver cómo se vive en cada situación la relación entre las mujeres y el Islam. 
En relación con estos aspectos se sitúan algunos de los retos y contradicciones que se le presentan al feminismo urbano "cuando se coloca en otros mundos diferentes a los suyos, como los que habitan las mujeres indígenas". Entre otros aspectos, el libro hace referencia a esa "deformación etnocéntrica hermenéutica" que lleva a las mujeres urbanas a creer que las indígenas están más oprimidas que ellas. Como advierte Sylvia Marcos, en realidad nos encontramos ante formas de opresión diferentes y de lo que se trata no es tanto de medir "cuánto" sino "cómo", a fin de descubrir las particularidades en la construcción de cada sociedad patriarcal.

Estacuestión apareceligada a una tendencia igualmente problemática, aquella que entiende que las mujeres indígenas, para liberarse de las formas de opresión que sufren, deben abandonar sus prácticas culturales. Los testimonios que se recogen en el libro muestran que las mujeres indígenas son conscientes de los obstáculos - "la incompletud" — de su cultura, las formas de opresión patriarcal que sufren en sus comunidades y pueblos y la necesidad de luchar por ciertos cambios. El concepto de "Teoría de la posicionalidad" sistematizado por la feminista afroamericana bell hooks permite explicar a Sylvia Marcos que el proyecto de recuperación selectiva de sus configuraciones ancestrales y la creación de una sociedad no sexista no son dos proyectos distintos, sino que están interconectados. Ellas desean al mismo tiempo preservar y conservar su cultura. En este sentido, las zapatistas son ejemplo de cómo unir las luchas como mujeres con las luchas de los pueblos indios, pues no podemos olvidar que sus derechos (colectivos) como mujeres indígenas se definen en el marco del reconocimiento de la autonomía de los pueblos indígenas.

$\mathrm{Al}$ referirse a la especificidad de las luchas de las mujeres indígenas mexicanas, el libro no sólo recoge sus dificultades al colocarse frente al feminismo urbano, sino también destaca su aportación a los movimientos de mujeres. Los múltiples encuentros en los que Sylvia Marcos ha tenido la oportunidad de participar, y los documentos y estrategias consensuados en ellos, ponen de manifiesto el protagonismo que desempeñan las mujeres en los movimientos indígenas y campesinos y el modo en que han sabido apropiarse y reformular muchas de las propuestas del feminismo. La CONAIE del Ecuador, el movimiento indígena boliviano que apoya a Evo Morales, el Movimiento de los Sin Tierra en Brasil y otras organizaciones integrantes de la Vía Campesina muestran, como las zapatistas, cómo sus prácticas de organización y lucha rompen con el doble estereotipo de la pasividad femenina y de la pasividad indígena.

Pero además, los movimientos de mujeres tienen mucho que aportar a los movimientos antisistémicos en general. La autora nos recuerda ciertas prácticas patriarcales que se resisten a desaparecer, como aquella que tiende a calificar las reivindicaciones y análisis feministas como "un asunto sólo de mujeres", considerándolos muchas veces como secundarios. Mientras tanto, las organizaciones de mujeres y movimientos feministas 
trabajan por elaborar propuestas que atañen a todos y construir alternativas integrales. Movimientos y redes internacionales - situadas abajo y a la izquierda - como la Marcha Mundial de Mujeres, la Red de Mujeres transformando la Economía o el Enlace Continental de Mujeres Indígenas son algunas de las organizaciones citadas que buscan, en esta línea, establecer ejes transversales de lucha.

Me gustaría cerrar esta recensión rescatando algunas cuestiones planteadas en el libro en relación con el vínculo entre academia y activismo que consideramos son de gran interés para el espacio que ocupa la Revista Andaluza de Antropología. A partir de su propio recorrido en la investigación académica, que le permite señalar la evolución que experimentan los estudios de género en México, la autora hace referencia a esa primera etapa, en los años setenta, en la que el compromiso de las académicas estaba estrechamente ligado a la militancia en el movimiento feminista. Esta relación, que les permitía moverse continuamente de la teoría a la práctica, se ha perdido en muchos casos en el momento actual. Junto a esta situación, señala otra problemática que está suscitando importantes debates y que hace referencia a la neutralización que han sufrido ciertos análisis feministas en el último periodo. Como plantea Sylvia Marcos, el feminismo no debe conformarse con ajustarse a lo "políticamente correcto" o a los límites establecidos por las instituciones, por el contrario, debe aspirar a cuestionar las estructuras sociales, históricas y políticas en las que estamos inmersos. El presente libro, y por supuesto las experiencias de las mujeres indígenas que se recogen en él, plantean la necesidad de mantener ese vínculo permanente entre academia y activismo y de no abandonar, en el camino, el espíritu de lucha y transformación social.

\section{Referencias bibliográficas}

DAVIS, Ángela Y. (2004 [1981]): Mujeres, raza y clase social, Akal, Madrid. hooks, bell (1981) Ain't I a woman. Black women and feminism. Boston: South End Press. hooks, bell (2004 [1984]) “Mujeres negras. Dar forma a la teoría feminista”. En VV.AA., Otras inapropiables. Feminismos desde las fronteras. Madrid: Traficantes de Sueños, pp. 33-50.

MOHANTY, Chandra Talpade (2002) "Encuentros feministas: situar la política de la experiencia”. Barret, M. y Phillips, A. (comp) Desestabilizar la teoría. Debates feministas contemporáneos. México: Paidós, pp. 89-106. 